\title{
Moral Relativism and Moral Absolutism: A Comparative study of Gilbert Harman and David B. Wong
}

\author{
Dr. Ratugamage Asha Nimali Fernando \\ Department of Pali and Buddhist Studies, University of Sri Jayewardenepura, Sri Lanka.
}

\begin{abstract}
This study examines the long-standing dispute between the moral relativist and moral Universalist. Relativism is recent years has been in the ascendancy in intellectual circles and has been associated with the intellectual fashions of different discipline in philosophy. Therefore, it is necessary to re-examine the nature of moral judgment and its application to present metropolitan world. In this scenario modern moral relativist Gilbert Harman made an excellence contributes to develop and clarify the concept of moral relativism. According to him, it has no a single true morality. There are a variety of possible moralities or moral frames of reference, and whether something is morally right or wrong, good or bad, just or unjust, etc. is a relative matterrelative to one or another morality or moral frame of reference. Something can be morally right relative to one moral frame of reference and morally wrong relative to another. David B Wong argues that a relativist theory can account for a considerable measure of moral objectivity and that it provides maximal reconciliation between those features of experience suggesting moral objectivity and moral subjectivity. Wong believes that the relativism can provide the best explanation to the diversity and disagreement of moral belief. He aware that absolutes have ways of trying to explains diversity and disagreement but in the end he argues that their explanations are inadequate. Wong go beyond the relativism and he introduced the new concept that is pluralistic relativism. This research paper will introduce and evaluate relativistic thoughts on morality from Harman and Wong in comparatively.
\end{abstract}

Key words: Moral Relativism, Universalism, value pluralism, Moral ambivalence.

\section{Introduction}

The main purpose of this study is to provide an analysis and evaluation of moral relativism (and moral absolutism). This analysis will be based mainly on a thorough investigation into the views of Gilbert Harman and David B. Wong, because these two philosophers present the most up to date and most plausible versions of moral relativism today. Therefore, I will compare and evaluate Harman`s and Wong`s moderate forms of moral relativism in particular in order to get a better understanding of the prospects of moral relativism (and absolutism) in general. This paper consist with three sections, the section one is concerned with characterizing the concepts of relativism, moral relativism and moral absolutism. Section two critically examines Harman's version of moral relativism. Section three discusses David B. Wong's theory of moral relativism, under that I came to my own conclusion.

\subsection{Section One: Characterizing the Concepts of Relativism, Moral Relativism and Moral Absolutism}

Relativism might appear to be a rather antiquated philosophical view, yet still keeps reappearing again and again braced with new arguments. The debate about relativism could, therefore, be considered an unfinished, or rather unending debate in philosophy-more so in moral philosophy. It, therefore, is not unreasonable to think that relativism has the claim to be reckoned as one of the significant themes of philosophical discourse in modern moral philosophy.

As a matter of fact, the concept of relativism appears to have noticeably changed the way morality has been treated in modern society. The idea of relativism arises out of an acknowledgement of the existence of deep 
differences in attitudes and beliefs in relation to human behavior. In the wake of political ideologies with global and universal aspirations, relativism has come to occupy a prominent place in the intellectual ethos of our times. ${ }^{1}$ In other words, it has become a constant theme in the theoretical orientation of various fields, including the social sciences, literary theory and cultural studies.

Relativism has assumed different forms and keeps on giving rise to many theoretical varieties. There are, as a matter of fact, different areas and kinds of things about which we can be relativists. We can, for instance, be relativists about knowledge, about art, culture, morality and many other philosophical problems. Relative judgments are arrived at in relation to a problem by making essential reference to something else, to which it is compared, related to or depends on for its meaning and justification. The validity of such a judgment, therefore, depends upon the context in which it is made. Relative judgments, then, stand contrasted against absolute judgments. A judgment is absolute if its truth or falsity is dependent only on facts about the object the judgment is concerned with, and not on facts beyond that. Relativism goes against this absolutistic stand and challenges the validity of such judgments with reference to analogical or relevant and comparable issues. For instance, regarding moral relativity, it is argued that morality is relative that moral judgments are only true or false relative to the standard that they are based on. There is no absolute standard available. In this sense moral relativism presents the notion that there is no global, universal or absolute moral law that applies to all people at all times, in all places. Instead of an objective moral law it espouses a qualified view where morals are concerned, especially in the areas of individual moral practices where personal and situational encounters supposedly dictate the correct or rather valid moral position.

We may also identify moral relativism as the view that holds that the truth or falsity of moral judgments is essentially relative to a particular standpoint or context; for instance, that of a culture or a historical period, and therefore, no standpoint is uniquely privileged over any other. It has often been associated with other claims about morality. For example, with claims like;1) the thesis that different cultures often exhibit radically different moral values;2) the denial that there are universal moral values shared by every human society;3) the insistence that we should refrain from passing moral judgments on beliefs and practices that characterize cultures other than our own.

There are three main varieties of moral relativism, viz: descriptive, normative and meta-ethical. ${ }^{2}$ Descriptive moral relativism is based on empirical facts. It is based on the observation that different cultures have different moral standards. Normative moral relativism is the view that what is morally required of individuals varies from group to group, culture to culture and so forth. Meta-ethical relativists, roughly, maintain that moral judgments, taken at face value, are neither true nor false, interpreted relativistically they are true or false. ${ }^{3}$

\subsubsection{Absolutism, Universalism}

Absolutism, universalism and objectivism in morality are some views opposed to moral relativism. It is important to discuss the nature of the concept of absolutism in briefly. Fred Feldman defines absolutism in the following words:

Absolutism is the view that there is one criterion of morality valid for all people at all times [...] it is the view that there is a single ultimate moral standard. ${ }^{4}$

Moral absolutism is contrasted with moral relativism. According to moral absolutism moral systems are absolute, perfect, and unchangeable. Robert Arrington says:

[...] Absolutism being the view that there is a set of moral standards or principles governing how all rational human beings should behave, relativism and absolutism are generally taken to be polar opposite $[\ldots]^{5}$

${ }^{1}$ Baghramian, M, (2004), The Problem of Philosophy: Relativism, Routledge Publisher, p.139.

${ }^{2}$ Harman, G. (2000), Explaining Values and Other Essays in Moral Philosophy, Oxford University Press, p.20.

3 ibid., p.20.

${ }^{4}$ Feldman, Fred (1978), Introductory Ethics, Englewood Cliffs, N.J.: Prentice-Hal, p. 162.

${ }^{5}$ Arrington, R.L. (1989), Rationalism, Realism and Relativism: Perspectives in Contemporary Moral Epistemology, Cornell University Press, p.193. 
Absolutism in meta-ethics is the view that moral judgments can be objectively correct or incorrect, and that they are not dependent on what anyone believes. Utilitarianism is absolute in this sense, because it's standard tells us what the objectively right way to act is. Absolutism in ethics is the claim that certain types of action are absolutely wrong always, i.e. they do not depend on situations for their rightness or wrongness. This may be because a wrong action does not respect the nature of human beings or their dignity or their freedom.

Moral absolutism itself may be divided into two positions, namely, descriptive moral absolutism and meta-ethical moral absolutism. Descriptive moral absolutism is the thesis that there does not exist any profound moral disagreement between societies, groups, cultures or individuals. ${ }^{6}$ Meta-ethical moral absolutism is the thesis that with regard to any existing differences between moral values in different cultures, societies, or in individuals, there are moral principles that are absolute or objective, and that they are universally true across cultures, societies or individuals. ${ }^{7}$

\subsection{Section two: Gilbert Harman's Argument for Moral Relativism}

Gilbert Harman, an American philosopher and well-known moral relativist have made a significant philosophical contribution to modern moral philosophy. As a moral relativist Harman's role in the development of the argument for moral relativism is significant. His thesis and arguments for moral relativism come from his publications such as The Nature of Morality (1977), "Moral Relativism Defended"(1975), "What is Moral Relativism?", Values and Morals (1978), 'Moral Relativism and Moral Objectivity (with J. Thomson in 1996) etc. Harman tried to reform moral relativism, as he believed that the standard version of moral relativism does not work. Therefore, he developed a subtler and more moderate form of relativism to meet the standard objections to relativism.

Harman studies moral relativism in contrast to moral absolutism, which holds that there is a single true morality. He considers moral absolutism as a view about the moral reasons that people have for their actions. He says:

I will understand a belief about absolute values to be a belief that there are things that everyone has a reason to hope or wish for. To say that there is a moral law that 'applies to everyone' is, I hereby stipulate, to say that everyone has sufficient reasons to follow that law. ${ }^{8}$

Moral relativism stands against moral nihilism as well. According to it there is no single true morality; and moral nihilism "takes this to be a reason to reject morality altogether including any sort of relative morality." "The moderate form of nihilism, however, asserts that there are moral facts, but there is no way to know them. On the other hand, we normally assume that moral responsibility depends on knowledge. This can explain why we consider animals as not being subject to morality. The striking conclusion would be that no one could ever do anything morally wrong. Therefore, nihilism completely undermines morality. Moral relativism, instead, asserts that "morality should not be abandoned" and "relative moral judgments can continue to play a serious role in moral thinking." In, "The Nature of Morality', Harman says that he is neither denying nor asserting that some moralities are "objectively" better than others or that there are objective standards for moral assessment. Harman tries to develop the concept of morality in a new direction. Ideas he had during in his earlier phrase helped him later to form his mature robust understanding of moral relativism. Harman investigates recent moral issues like abortion, war, and equality with this new approach. In this new approach he questions these moral issues by considering concepts like, nihilism, functionalism, naturalism and emotivism. In addition, he introduced new arguments to the debate of morality. Following I will consider his modern version on moral relativism.

\footnotetext{
${ }^{6}$ Philip Brey (2000), "Is Information Ethics Culture - Relative?" in Selected Readings on the Human Side of Information Technology, Ed. Edward J. Szewczak, Canisius College USA, p.31.

${ }^{7}$ Philip Brey (2000), "Is Information Ethics Culture - Relative?" in Selected Readings on the Human Side of Information Technology, Ed. Edward J. Szewczak, Canisius College USA, p.31.

${ }^{8}$ Harman, G. (1998a), "Precis of Moral Relativism and Moral Objectivity", in, Philosophical and Phenomenological research, Vol. LVII, No1, Marchp.370.

${ }^{9}$ Harman, G. \& J.L. Thomson (1996), Moral Relativism and Moral Objectivity, Cambridge University Press, p.5.

${ }^{10}$ Ibid., p.6.
} 


\subsubsection{Harman's Robust Understanding of Moral Relativism}

Harman formulates his mature doctrine of moral relativism in his book, Moral Relativism and Moral Objectivity (1996: Harman and J.J Thomson). It is based on five statements. Those are the following.

(a) For the purpose of assigning truth conditions, a judgment of the form, the mass of $X$ is $M$ has to be understood as elliptical for a judgment of the form, in relation to spatio-temporal framework $F$ the mass of $X$ is $M .^{11}$ (original in italics)

(b) For the purposes of assigning truth conditions, a judgment of the form, it would be morally wrong of $P$ to $D$, has to be understood as elliptical for a judgment of the form, in relation to moral framework $M$, it would be morally wrong of $P$ to do $D$. Similarly for other moral judgments. ${ }^{12}$ (original in italics)

(c) There is no single true morality. There are many different moral frameworks, none of which is more correct than the others. ${ }^{13}$

(d) Morality should not be abandoned. ${ }^{14}$

(e) Relative moral judgments can continue to play a serious role in moral thinking ${ }^{15}$.

These statements (a), (b), (c), (d) and (e), are different parts of his understanding of moral relativism. To understand his entire case for his mature moral relativism, we will have to analyse the above statements that were presented by Harman. Statement (a) is important because an extended comparison between morality and physics. In statement (b) Harman introduces the concept of a moral framework. In statement (c) he denies the universality of morality. Also he accepts the diversity of moral thinking.

\subsubsection{The Role of Moral Frameworks in Harman's Theory}

First of all, to get a clear understanding of the Harman's statements (a), (b), (c), (d), (e), it is necessary to explain what Harman means by a moral framework, for his formulation of moral relativism will be meaningless without a clear understanding of the concept of a moral framework. Harman suggests that "a moral framework can be understood on the model of the laws of one state, where the laws together with the 'facts of the case' determine whether something is legal nor not." and principles that one accepts, but it cannot be identified with them. Harman thinks that it is possible to conceive of people making mistakes about moral issues in relation to their moral frameworks. Harman says that there is no common answer among relativists as to how one's actual values determine the relevant moral framework.

Harman believes that moral right and wrong are relative to one or the other moral framework. As well, there may be various different moral frameworks, none of which is objectively more correct than the others. To assess a moral judgment for truth, we first translate it into a moral framework. This moral framework frequently will be our own moral framework, but it could also be the moral framework of the maker of the judgment or of the audience of the judgment or of the person who is the object of the judgment. Harman states, "Any moral framework has to be consistent." ${ }^{\text {"17 }}$ Therefore, inconsistent moral frameworks are not acceptable. He also thinks that some moral claims might be true in relation to all moral frameworks, just like the physical claim that

\footnotetext{
${ }^{11}$ Harman, G \& Thomson, J.J (1996), Moral Relativism and Moral Objectivity, Blackwell, Cambridge, Mass, p.4.

${ }^{12}$ Ibid.

${ }^{13}$ ibid.,, p.5.

${ }^{14}$ Ibid., p.6.

${ }^{15}$ Ibid., p.7.

${ }^{16}$ Harman, G. \& Thomson, J.J (1996), Moral Relativism and Moral Objectivity, Blackwell, Cambridge, Mass, p.5.

${ }^{17}$ ibid., p.208.
} 
nothing moves faster than light is true in relation to all spatio-temporal frameworks. Naturally, every moral claim that is not compatible with universal claims is wrong in relation to all moral frameworks, but he believes that no substantive central core of morality is universally recognized.

In Harman's view the most plausible explanation for the actual moral phenomena is the operation of a wide variety of different moral frameworks. From this he believes that we can reasonably infer that moral relativism is true. While he is aware that moral diversity in itself does not entail moral relativism, Harman tries to show that it is more reasonable to infer that moral relativism is true than that anything else is.

\subsubsection{Harman Arguments Against Moral Universalism}

A possible universalist explanation of moral diversity that has become prey to criticism of Harman is the argument from universal demand. As Harman himself sums up: "According to moral absolutism [...] there is a single moral law that applies to everyone; in other words, there are moral demands that everyone has sufficient reasons to follow, and these demands are the source of all moral reasons. Moral relativism denies that there are universal moral demands, and says different people are subject to different basic moral demands depending on the social customs, practices, conventions, values, and principles that they accept." ${ }^{18}$ According to this universalist account, such individuals or groups may have the same relevant experiences as those who are following the universally correct moral system; but their false beliefs about non-moral matters lead them to misinterpret this experience and so they end up adopting moral arrangements that are not correct.

Disagreeing with this explanation, Harman believes that this kind of account of moral diversity is the result of a simple bias in favour of one's own moral framework: "The system of moral coordinates that is determined by a person's own values can be so salient that it can be seen by that person to have a special status." ${ }^{19} \mathrm{~A}$ commitment to moral universalism in itself provides no guarantee that the moral universalist's own moral framework is actually the universally correct moral framework.

\subsubsection{The Formation of a Soberly Logical Thesis}

Our discussion above has made clear that Harman has effectively attempted a rejection of universalism in favour of accepting the possibility of a relativistic stand in moral theory. This line of argumentation has lead Harman to create a "soberly logical thesis." In presenting his logical thesis, Harman shows that most so-called relativists seem to simply define moral relativism as an inconsistent thesis ${ }^{20}$ and they used to be committed to the following triad of premises:

(a) There are no universal principles.

(b) One ought to act in accordance with the principle of one's own group.

(c) Principle (b) is a universal moral principle. ${ }^{21}$

Harman, however, not finding this very satisfactory, suggests that we should view moral relativism as a 'soberly logical thesis'. Harman is not denying, nor is he asserting that some moralities are objectively better than others or that there are objective standards for moral assessment. He pointed out,

My moral relativism is a soberly logical thesis-a thesis about logical form, if you like. Just as the judgment that something is large is true or false only in relation to one or another comparison class, so too, I will argue, the judgment that it is wrong of someone to do something is true or false only in relation to an agreement or understanding. A dog may be large in relation to Chihuahuas but not large in relation to dogs in general. Similarly, I will argue, an action may be wrong in relation to one agreement

\footnotetext{
${ }^{18}$ Harman, G. (2000), Explaining Values and Other Essays in Moral Philosophy, Oxford University Press, p. 85. ; See also Harman, (1985), 'Is There a Single True Morality?, in David Copp and David Zimmerman (eds.),Morality, Reason and Truth (Totowa, N. J.: Rowan and Littlefield),pp.27-48.

${ }^{19}$ Harman, G. \& Thomson, J.J (1996), 'Moral Relativism and Moral Objectivity', Blackwell Publishers, p 13.

${ }^{20}$ Williams, B. (1972), 'Morality: An Introduction to Ethics', New York: Harper \& Row, pp. 20-21 and Singer, M. (1961), 'Generalization in Ethics: An Essay in the Logic of Ethics, with the Rudiments of a system of Moral Philosophy', Network: Athenaeum, p.332.

${ }^{21}$ Harman, G. (2000), Explaining Value and Other Essays in Moral Philosophy, Oxford University Press, p.3.
} 
but not in relation to another. Just as it is indeterminate whether a dog is large, period, apart from any relation to a comparison class, so too, I will argue, it is indeterminate whether an action is wrong, periods, apart from any relation to an agreement. ${ }^{22}$

This so-called "soberly logical thesis" of Harman was clarified by Carol Rovance in The Metaphysics and Ethics of Relativism (2013) Rovance explains that "The form of moral relativism that Harman defends is, in his words, a soberly logical thesis. Given that inner moral judgments make sense only in relation to particular moral agreements, any adequate account of their logical form should make this explicit. This logical thesis may seem reminiscent of the semantic relativist's proposal that [...], to portray moral truth as relative to moral context." ${ }^{23}$ I can agree with Rovance`s understanding of Harman`s thesis.

\section{Inner Judgments}

In Harman's attempt to provide the most plausible account of moral relativism we may identify two main premises or grounds. One is the logical thesis that moral relativism applies only to those moral judgments he calls 'inner judgment'; the other is the claim that agents are motivated to act morally as a result of an agreement in intentions that arise due to what he calls 'implicit bargaining'. I will look at each in turn once again in somewhat more detail.

For Harman, an inner judgment is a judgment we can make about a person, "only if we suppose that he is capable of being motivated by the relevant moral considerations." 24 Examples of inner judgments include a judgment that someone ought or ought not to have done something and a judgment that it was right or wrong of someone to have done something.

Harman draws a logical distinction between four different senses of the word "ought." These are what he calls the expectational sense, the rational sense, the normative sense and the moral sense. ${ }^{25}$ For example, the sentence: "she ought not to have an abortion", may be interpreted in at least four different ways, employing each of the above four senses respectively. The sentence may mean that 1) one would not expect her to have an abortion, or that 2) it would not be in her own best interests to have an abortion, or that 3) it would a bad thing for her to have an abortion, or that 4) she would be morally wrong to have an abortion. According to Harman, it is only the very last of these interpretations of this sentence that makes it an inner judgment, and it is this kind of judgment that Harman's theory of moral relativism solely applies to. This distinction between the third and the fourth sense of "ought" is a fine one, but not important for Harman. He explains it thus:

The normative "ought to be" is used to assess a situation; the moral "ought to do" is used to describe a relation between an agent and a type of act that he might perform or has performed. ${ }^{26}$

Harman also thinks that this is the case with the word "wrong" as well. He opines that it is important to distinguish between using the word "wrong" to mean that a particular situation or action is wrong form using the word to say that it is wrong of someone to do something. ${ }^{27}$

The point of the distinction seems to allay the universalist's fear that moral relativism can allow anything to be morally acceptable by to say something like this: the situation that obtained in ancient Greece that allowed human slavery to be practiced was a morally wrong situation, but that despite this it was not morally wrong for individual ancient Greeks in that situation to enslave humans.

Harman singles out inner judgments as being susceptible to relativism because they imply that the agent who is the agent of the inner judgment has a reason (or reasons) to do or to refrain from an action and that the one

\footnotetext{
22 ibid.,p.4.

${ }^{23}$ Rovance, Carol (2013), The Metaphysics and Ethics of Relativism, Maria Mores, USA, p.231. The same understanding of Harman`s logical thesis we can see in; Sadurski, W. (1990), Moral Pluralism and Legal Neutrality, Kluwer Academic Publisher, p.72.

${ }^{24}$ Harman, G. (1982), 'Moral Relativism Defended' in Relativism: Cognitive and Moral. M. Krausz and J. Meiland (eds.), University of Notre Dame Press, p.190.

${ }^{25}$ ibid., p.192.

${ }^{26}$ Harman, G. (1982), 'Moral Relativism Defended' in Relativism: Cognitive and Moral. M. Krausz and J. Meiland (eds.), University of Notre Dame Press, p.192.

${ }^{27}$ Ibid.
} 
making the judgment approves of this reason (and that the intended audience for the judgment also approves). So, it implies that inner judgments may only legitimately be made relative to a set of shared reasons for acting. One may not make a genuine inner judgment that someone ought or ought not to do something about whom the judgment is made. This is the logical foundation of Harman's moral relativism. He analyzes 'ought' when used in the moral sense, as a four-place predicate, in the following manner:

'Ought (A, D, C, M)' which relates an agent A, a type of act D, considerations $\mathrm{C}$, and motivating attitudes M. ${ }^{28}$

The inclusion of $\mathrm{M}$ guarantees that a reference to shared motivating reasons for acting is built into the meaning of the moral sense of 'ought.' Although in this analysis Harman does not mention the notion of the framework that takes center stage in his later writings on relativism, a framework may be supposed to be constituted by a set of shared motivating reasons for acting. Harman acknowledges that his analysis requires the following assumption:

"I assume that the possession of rationality is not sufficient to provide a source for relevant reasons (for action), that certain desires, goals, or intentions are also necessary." ${ }^{29}$

However, even those who did not accept this assumption about the role of rationality in motivating action would not need to reject Harman's analysis of inner judgments entirely, but would only need to insist that the inclusion of a reference to motivating attitudes is a redundant element, as speaker and audience will always necessarily share motivating attitudes of any action if they are all rational. Someone with this view might want to insist that, strictly speaking, the word 'ought' when used in a moral sense is a three-place predicate and not a four-place predicates as Harman believes. Making this modification would allow Harman's analysis of moral judgments to be detached from his moral relativism and they could each stand alone as independent contributions to metaethics.

\subsection{Section three - David B. Wong's Argument for Moral Relativism}

The American philosopher David B. Wong has made significant contributions to metaethics, moral psychology, Chinese ethics and comparative ethics. His academic research covers many areas of different traditions of ethics but moral relativism is the center of all. Wong's 'Moral Relativity' (1984) is a pioneer work on moral relativism, and his book 'Natural Moralities: A Defense of Pluralistic Relativism' (2006) articulates and defends an ethical theory that is pluralistic, relativistic and naturalistic in nature. Wong's pluralistic relativism is a sophisticated and attractive alternative to extremist views on relativism. At the same time he believes that moral relativism is the only way to avoid conflicts in our current multicultural society. ${ }^{30}$

Wong is working in Chines philosophy too; he has published several articles and books about Chinese philosophy and Chinese ethics. ${ }^{31}$ Most important in his philosophical thought is the mixing of ancient eastern ethics with modern western topics. We can see that Wong's naturalism is a combination of Xunzi's naturalistic and functionalist account of morality and Zhuangzi's emphasis on the virtue of accommodation. ${ }^{32}$ Wong has combined Xunzi`s and Zhuangzi`s philosophical thoughts with scientific studies of human nature in the humanities and social sciences. So in this way Wong connects science and philosophy as well as eastern

\footnotetext{
${ }^{28}$ Harman, G. (1982), 'Moral Relativism Defended' in Relativism: Cognitive and Moral. M. Krausz and J. Meiland, (eds.), University of Notre Dame Press, p.192.

${ }^{29}$ Ibid., p.194.

${ }^{30}$ Wong says: " Moral relativism is a common response to the deepest conflicts we face in our ethical lives. Some are quite public and political, such as the disagreement in the USA over moral and legal permissibility of abortion. Other conflicts inviting the relativistic response are of a less dramatic but more recurrent nature, such as the feeling of a first generation Chinese American who faces conflicts between inherited values and the values of the adopted country.") See, David B. Wong (1996), "Relativism", in P. Singer ed., A Companion to Ethics, Oxford : Blackwell publishers, p.445.

${ }^{31}$ Here are some of them: David B. Wong (co-editor) 'Confucian Ethics: A comparative Study of Self, Autonomy and Community' (Cambridge University Press 2004); “Xunzi on Moral Motivation.” In Chinese Language, Thought, and Culutre: Nivison and His Critics, ed. Philip J. Ivanhoe, (1996), pp.202-223; "Reasons and Analogical Reasoning in Mengzi." In Essays on the Moral Philosophy of Mengzi, ed. Xiusheng Liu and Philip J. Ivanhone, Indianapolis: Hackett (2002), pp.187-220 etc.

${ }^{32}$ Xiao Yang and Human Yong, Eds. (2014) Moral Relativism and Chinese Philosophy, State University of New York, p.ix.
} 
ideologies of morality with the western debate about modern morality. He distinguishes between two conceptions of morality one based on the rights of individuals (right-centered moralities), and the other one focused on the promotion of the good of the community (virtue- centered moralities). ${ }^{33}$ Wong defends first of all the idea that there can also be democratic rights based on the idea of community. Then he puts forward the view that the very ideas of right and community are interdependent and that both are necessary to realize democratic values. As the notion of a common good is problematic, he finally advocates a community that is open to pluralism and capable of settling its differences through mechanisms of arbitration and conciliation.

Wong further proposes that there can be a plurality of true moralities; different moralities exist in different traditions and cultures, but all of them address accepts of the same problem: how we are to live well together. To prove this he examines a wide array of positions and texts within the western canon as well as in Chinese philosophy, history and literature, to make a case for the importance of pluralism in moral life, and to establish the virtues of acceptance and accommodation. Wong's point is that there is no single value or principle or ordering of values and principles that offers a uniquely true path for human live but variations according to different contexts that realize within them a common core of human values. We should thus be modest about our own morality, learn from other's approaches, and accommodate different practices in our pluralistic society.

Wong forms his theory of adequate moral systems and morality as a social creation in his first publication on Moral Relativity (1984) and he develops his theory in the later work titled Natural Moralities: A Defense of Pluralistic Relativism (2006).

\subsection{Six Claims to Characterize Objectivity and Subjectivity in Morality}

David B. Wong, in his book Moral Relativity, proposes a theory that, according to him, "gives us the best explanation of moral experience." "It is "a theory built around the claim that there is no single true morality," ${ }^{35}$ Wong characterizes the metaethical dispute about this claim in terms of conflicting views on whether morality is "objective" or "subjective." He believes that in morality the terms "objective" and "subjective" form a family of characteristics that are frequently found together in descriptions of the nature of morality, but are not necessarily related. Wong lists six claims on the first page of his book. Depending on how many of them one agrees to one is an "objectivist" or "subjectivist" about morality is worth examining. The claims are:

1. Moral statements have truth values;

2. There are good and bad arguments for the moral positions people take;

3. Nonmoral facts (states of affairs that obtain in the world and that can be described without use of moral terms such as "ought", "good" and "right") are relevant to the assessment of the truth value of moral statements;

4. There are moral facts (that may or may not be claimed to be reducible in some way to nonmoral facts);

5. When two moral statements conflict as recommendations to action, only one statement can be true;

6. There is a single true morality. ${ }^{36}$

Wong rejects claim 6 , correctly identifying it as being the real issue that separates moral universalists from moral relativists. He recognizes that a moral relativist may accept, at least, claims 1-4, while it would be possible for a moral universalist to deny them. Claim 5 seems to be the odd one in this list as acceptance or denial of it would depend greatly on just how conflicting are the two moral statements as recommendations for action. Wong seems to think that the two moral statements must contradict one another. The example he gives of

\footnotetext{
${ }^{33}$ Wong, B. David (1984), Moral Relativity, Berkeley: University of California Press, p. 160; see also, Wong, B. David (2000) "Moral Relativity and Tolerance" in Moral Disagreements: Classic and Contemporary Reading, (eds.) Gowans, W. C, Routledge Publishers, pp.141-156.

${ }^{34}$ Wong, B. David (1984), Moral Relativity, University of California Press, p.1.

${ }^{35}$ Ibid.

${ }^{36}$ Wong, B. David (1984), Moral Relativity, University of California Press, p.1.
} 
two conflicting moral statement is "you ought not to act coldly" and "you ought to act coldly.",37 However, less opposed pairs of conflicting moral statements seem to be possible, such as in a situation that might be described as a moral dilemma, perhaps a case in which someone has made a promise that requires them to tell a lie, in which moral recommendations to action may conflict without, strictly speaking, contradicting each other. The acceptance or rejection of claim 5, therefore, depends on the details and will not necessarily separate the moral universalist from the moral relativist.

Wong commits himself to accepting claims 1-4: that moral statements have truth values, that there are good and bad arguments for the moral positions people take, that non-moral facts are relevant to assessing the truth values of moral statements, and that there are moral facts. But he rejects the claims 5-6: he believes that two moral statements recommending conflicting courses of action can both be true and that there is no single true morality. ${ }^{38}$ Wong categorizes himself as a moral relativist, but at the same time he wants to take on board some of what he thinks are the more plausible of the claims that moral universalists might make. Wong wishes to achieve a compromise between moral relativism and moral universalism by conceding some claims that are often accepted by and central to a universalist account of morality while at the same time, insisting that the nature of morality is ultimately relativistic. The strategy is to give moral universalists almost all they could reasonably ask for but still in the end maintain a theory that would deserve to be called a form of moral relativism.

Wong, like Harman, critically examines some common universalist strategies for explaining moral diversity and disagreement. The universalist might say that in a moral disagreement one side or the other side is mistaken about some fact or facts, or that one side or the other has made errors is reasoning, or that the disagreement is beyond the powers of human reason to solve. ${ }^{39}$ Wong thinks that the universalist is not able to satisfactorily explain just what the facts are that one side or the other is mistaken about. Nor does he believe that universalists are able to say just what errors in reasoning have taken place, or why exactly the disagreement is beyond human power to solve. "The general failing of the absolutist methods is not meeting the principle of the best explanation. We are left with gaping holes in our theory of the speakers of moral language." ${ }^{40}$ Here Wong`s relativism, in very much the same way as Harman`s, starts from the claim that universalists are not able to give an acceptable explanation of why moral diversity occurs.

\subsection{The Main features of the Thesis of Pluralistic Relativism}

Wong's argument for moral relativism in his early publication, [Moral Relativity, (1984),] was developed and in some respects and he presented it in his recent publication on, Natural Moralities: A Defense of Pluralistic Relativism (2006). In this book he introduces a new thesis about moral relativism. He labels his theory 'pluralistic relativism.' Wong`s attempt is not to investigate whether relativism is true or not; he rather wants to turn this debate in a new direction: To find out most applicable relativist position to plural society. His so-called 'pluralistic relativism' contains two major themes: it is relativistic because according to it there is no single true morality. It is pluralistic because it recognizes limits on what can count as a true morality. ${ }^{41}$

In this sense Wong believes that there is no single true morality but true moralities are multiple. Wong is rejecting the extreme form of relativism and the extreme form of universalism. In developing his theory Wong provides a deep analysis of diverse ethical theories in western and eastern moral traditions. And he emphasizes the importance of the virtue of accommodation in today's pluralistic world. Wong is accommodating one aspect of universalism, which is that there exist some universally valid criteria that all moralities have to meet. And he does not defend all forms of relativism; instead, he tries to find out what form of relativism is a defensible one by drawing on a broad set of empirical studies in natural and social sciences and the humanities.

Wong's pluralistic relativism is a cluster of ideas about morality; as well it is the co-existence of the several theories. Hence, in his formation of the theory of pluralistic relativism Wong uses several basic foundational ideas as an approach to his main theory. Therefore, to understand the theory of pluralistic

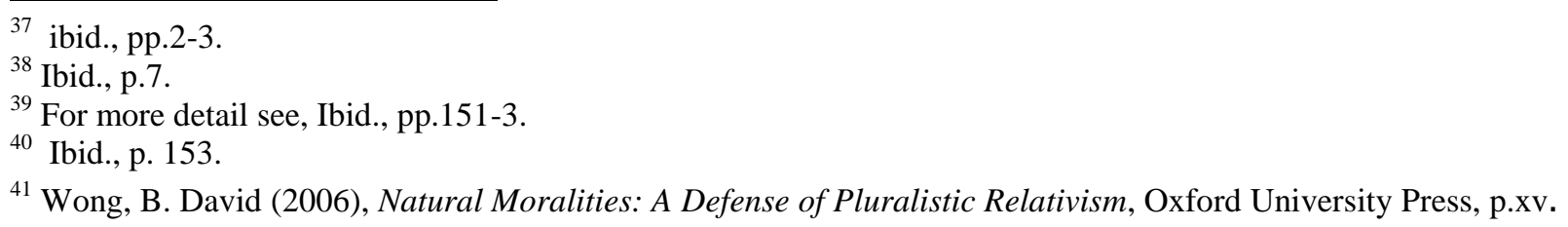


relativism it is necessary to get clear each and every parts of the theory. One important component again, is the concept of truth conditions of moral judgment; because Wong still believes that moral statements have truthvalues. He believes that the truth-conditions of moral judgments in a society must be determined by both logically contingent criteria and universally valid criteria.

The other important part of the theory of pluralistic relativism is the concept of 'moral ambivalence.' Wong believes this phenomenon to be widespread, and he thinks it is important to properly interpret and explain it. His interpretation is that moral disagreements that give rise to ambivalence typically involve a plurality of values such that the disagreeing parties accept the same values, but assign different priorities to them. Wong takes moral ambivalence to presuppose moral value pluralism, the view that there is an irreducible 'plurality of basic moral values.' Wong argues that moral ambivalence, interpreted as implying moral value pluralism, should be explained in terms of "methodological naturalism." 42 This leads him to pay attention to empirical inquiries, even for evaluating claims that purport to be a priori.

Another important idea is that of the two functions of morality. The first function of morality is to promote and sustain social cooperation. And the second function is to promote individual flourishing. In addition to that, Wong thinks human beings by nature have basic interests to have these functions fulfilled adequately: This includes physical needs, social needs, needs for knowledge, etc. Wong also explains and argues that these are naturalistic constraints on an adequate morality. He points out that a morality that promotes individual flourishing requires that we possess 'effective agency' that is, a set of abilities that allows us to formulate reasonably clear priorities among our ends, and to plan and perform actions that have a reasonable chance of realizing our ends. ${ }^{43}$ Effective agency depends in turn on having an 'effective identity', that is, a practical identity that includes self-esteem, an ability to balance its different aspects, and a capacity to determine the implications of social norms. Wong points out that other persons, in particular early in life care-takers, "have a deep effect on the formation of our characters, $[\ldots]$ "44 especially on the development and maintenance of effective identity and agency. The upshot of this is that an adequate morality must foster personal relations such as those in the family. As a result, the impersonal standpoint must be limited in some ways by the personal perspective, along with the partial duties to particular others that go with it. The other significant characteristic in Wong's pluralistic relativism is the thesis of accommodation. The value of accommodation he traced from the Chinese Daoist philosopher Zhuangzi and he reframes it according to the current diversity of morality to harmonize conflicting moral norms and beliefs. ${ }^{45}$

In what follows I will describe Wong's explanation of the universal dimension of morality or the universally valid criteria in morality and their place in his pluralistic thesis, and then I will move on to discuss what is the nature of moral ambivalence and the value of pluralism and it`s potential to reject moral universalism.

\subsection{Universal Dimension of Moralities}

Wong explains how morality has been developed in response to human needs and the circumstances of human life. He himself saw the limits of his earlier thoughts about the universally valid criteria of moralities. Wong in his Natural Moralities: A Defense of pluralistic relativism says that:

In this new book I primarily seek to further develop the relativistic themes defended in Moral Relativity. In that first book I primarily focused on the task of refuting universalism while defending a good measure of moral objectivity. My conception of the universally valid criteria for the adequacy of moralities was rather sketchy. In this book I offer a robust conception of such criteria, such that they rule out a significant range of moralities as inadequate. Whereas the first book focused on the relativity in my theory of relativism with limits, this book focuses to a much greater extent on the limits. ${ }^{46}$

Pluralistic relativism consists of many parts. One of them is a form of universalism according to which there are universally valid criteria such that, if a morality fails to meet the universally valid criteria, that morality

\footnotetext{
${ }^{42}$ ibid., pp.35-36.

${ }^{43}$ Wong, B. David (2006), Natural Moralities: A Defense of Pluralistic Relativism, Oxford University Press p.119.

44 ibid., p.134.

${ }^{45}$ See, Wong, B. David (2006), Natural Moralities: A Defense of Pluralistic Relativism, Oxford University Press, pp.234-7; Wong, B. David, (1984), "Taoism and the Problem of Equal Respect", in Journal of Chinese Philosophy, 11, p.173.

${ }^{46}$ Wong, B. David (2006), Natural Moralities: A Defense of Pluralistic Relativism, Oxford University Press, p.xiv.
} 
is inadequate. ${ }^{47}$ Inadequate moralities are not true moralities. We have mentioned earlier that Wong, in his pluralistic relativism, rejects the idea of extreme universalism or the belief of one single true morality, and that he accepts "a plurality of true moralities." 48 But from that he is not committed to the view that every actual morality is guaranteed to be a true one. He just believes that there can be more than one true morality.

\section{Conclusion}

In this paper, I have undertaken to review and discuss critically the long-standing dispute between moral relativism and moral absolutism. I have attempted, therefore, a philosophical clarification and comparison of the stands of moral relativism and moral absolutism. For this purpose, I have selected the views of two highly prominent contemporary thinkers in this debate, namely, Gilbert Harman and David B. Wong. I have perceived that the concept of relativism is not a unified doctrine when compared to other philosophical positions or problems within philosophy. It addressed the vast areas of human intellectual inquiry.

Harman takes the debate on moral relativism and universalism seriously. He pointed out that a philosophical discussion is necessary to understand the nature of moral diversity. He also admits that the mere existence of diversity cannot be an argument for ethical relativism. Harman understood that the debate over ethical relativism is interwoven with the debate about the foundations or origins of morality. Harman rejects the idea that right and wrong are determined by the particular individual's decisions and principles. He is a cognitivist and believes in the truth of value judgments. And he acknowledges that most people do not intent their judgments to be relational and this is why he says that his theory is not about the meaning of moral statements but it is a "logical thesis."

Harman in his recent publication (Moral Relativism and Moral Objectivity) presented an interesting analogy between morality and motion. He shows that it is only possible to judge whether something is morally right or wrong relative to some moral framework in the same way as it is only possible to judge whether something is in motion or rest relative to some spatio-temporal framework. The important point here is that everything is dependent on the framework within which we make our judgment, either about motion or morality. His view on moral frameworks plays a significant role in his moderate version of moral relativism. Harman, nevertheless, does not present his analogy between morality and motion as an argument for moral relativism. This analogy is an elucidatory device designed to bring about some understanding for his acknowledging the different moral frameworks within which people`s moral judgments are made and their moral principles operate. This point helps one to understand and accept that there are different moralities and moral judgments and that the truth-values of moral judgments are relative to frameworks. Therefore, moral judgments at face value are neither true nor false, because every moral judgment or principle is dependent and relative to a moral framework. This makes me to strongly believe that Harman's theory of moral relativism is essentially a meta-ethical theory.

Harman in his profound engagement with the controversy about moral relativity has indicated a new path for other moral philosophers. I would rather consider that to be his most important contribution to moral relativism. In fact, just accumulating data to understand the diversity of morality will not lead to a philosophical development of moral relativism. It is absolutely essential to study moral judgments and moral principles along with their grammar discover the relativity to moral frameworks. Harman's work has directed their search and provided necessary emphasis on the importance of philosophical and meta-ethical inquiry into moral relativism.

Harman has clearly stated that his relativism is a restricted one; it is about the moral ought or inner judgment. He claims this because he believes that there are aspects of our moral intuition that cannot be explained simply by appealing to the social custom theory. Of course there are many criticisms levelled against his concept of inner judgment and against his implicit bargaining theory.Wong's understanding of morality is more sophisticated than that of Harman, and it also goes beyond relativism. He was able to make clear what the nature of the debate about ethical relativism fundamentally is, and he showed that it is interwoven with the debate about the foundation and origin of morality. Based on this, Wong has developed his theory of adequate moral systems and the social creation of morality. This theory is in agreement with relativism: Due to the

\footnotetext{
${ }^{47}$ ibid., p.xiv.

${ }^{48}$ Wong says, "there is a plurality of true moralities, but that plurality does not include all moralities." See, Wong, B. David (2006), Natural Moralities: A Defense of Pluralistic Relativism, Oxford University Press, p.xii.
} 
contexts of differing social circumstances, different groups are led to operate with different extensions of the phrase 'adequate moral system.'

Wong agreed that one difficulty for the relativist account of morality is to explain how people can disagree with each other and how cross-cultural conflicts are possible. Wong tried to solve the problem via the notion of an adequate moral system. Referring to two different adequate moral systems, two moral judgments may equally well prescribe two different things. They are independent from each other and both can be true, because the conflict is only pragmatic and not logical. According to Wong's theory of morality, morality is rooted in human nature and real human needs. He takes morality to be a response to those needs. Therefore, the only reason to allow for relativity is that human nature is plastic enough to allow for alternative resolutions and, hence, alternative moral systems. Wong's theory is a modified version of relativism compared with that of Harman. His theory goes beyond relativism.

Finally, I felt that Wong in his relativism which he present in Moral Relativity, identified some areas himself which are weak. In his recent publications, however, Wong has avoided many of the weak areas in his earlier thinking on moral relativism. He introduced a naturalistic, pluralistic and relativistic theory, according to which different moralities are true and adequate. His value pluralism means that each morality endorses many different values, made coherent in a system, rather than a single system of values. His pluralistic moral relativism also means that there are many different ways to systematize the different values. In this sense moralities are multiple. In this way Wong's theory goes beyond relativism.

\section{Bibliography}

[1] Arrington, Robert L. (1989), Rationalism, Realism and Relativism: Perspectives in Contemporary Moral Epistemology. Ithaca, N.Y,: Cornell University Press.

[2] Baghramian, M. (2004), Relativism, London, New York: Rutledge.

[3] Baghramian, M. (2010), “A Brief History of Relativism.” in Relativism: AContemporary Anthology, ed., Michael Krausz, Colombia University Press.

[4] Brandt, Richard B. (1967), "Ethical Relativism", Paul Edwards (edit): The Encyclopedia of Philosophy, vol.III, MacMillan and Free Press, New York, pp.75-77.

[5] Bunting, H. (1996), “A Single True Morality? A Challenge of Relativism”,

[6] In Philosophy and Pluralism, ed., D. Archrd, Cambridge,S,pp.73-85.

[7] Copp, David (1982), "Harman on Internalism, Relativism and Logical Form”, Ethics 92:S,pp.227-42. https://doi.org/10.1086/292323

[8] Damien Anthony Cole (2004) Moral Relativism and Moral Universalism: A Coherentist Approach, University of Victoria, Wellington. Darwall, Stephen (1977), "Harman and Moral Relativism”, Personalist 58:S, pp.199-207.

[9] Driver, Julia (2007), Ethics: The Fundamentals, Blackwell Publishing. Garnett, A. Campbell (1944),"Relativism and Absolutism”, in Ethics, 54:S, pp.186-99.

[10]Gellner, Ernst (1982), "Relativism and Universalism"; in Martin, Hollis and Steven Lukes, eds., Rationality and Relativism, Massachusetts: M.I.T. Press.

[11] Gill, B. Michel (2014), Humean Moral Pluralism, Oxford University Press. https://doi.org/10.1093/acprof:oso/9780198714033.001.0001

[12] Hales, Steven D. (2006), Relativism and the Foundation of Philosophy, MIT Press.

[13] Harman, Gilbert (1977), The Nature of Morality: An Introduction to Ethics, Oxford University Press

[14] Harman, Gilbert (1982), "Moral Relativism Defended" in relativism:Cognitive And moral, Notre Dame, In.: University of Notre Dame Press, p.189-204.

[15] Harman, Gilbert (1984), "Is there A Single True in Morality?" in Morality, Reason and Truth: New Essays on the Foundation of Ethics. David Copp and David Zimmerman, eds., Totowa Roman and Allanheld, p.27-48.

[16] Harman, Gilbert \& Judith Jarvis Thomson (1996), Moral Relativism and Moral And Moral Objectivism, Cambridge, Mass,:Backwell. 
[17] Hinman, Lawrence M. (1998), "Ethics: A Pluralistic Approach to Moral Theory”, second edition, Fort Worth S. pp.3659.

[18] Kekes, John (1993), The Morality of Pluralism, Princeton University Press, Princeton.

[19] Kellenberger, James (2001), Moral Relativism, Moral Diversity and HumanRelationships, Penn State University Press.

[20] Kellenberger, James (2008), Moral Relativism: A Dialogue, Lanham.

[21] Kim, Hye-Kyung \& Wreen, Michael (2003), "Relativism, Absolutism and Tolerance", Metaphilosophy, vol 34(4), pp.447-459 https://doi.org/10.1111/1467-9973.00284.

[22] Ladd, John (ed.), (1973), Ethical Relativism, Belmont Publisher.

[23] Langenfus, William L. (1988/89), “A Problem for Harman's Moral Relativism”, Philosophy Research Archives 14:S, pp.121-36.

[24] Levy, Neil (2002), Moral Relativism, A Short Introduction, Oxford, London.

[25] Lomasky, Loren (1979), “Harman's Moral Relativism”, Journal of Libertarian Studies 3:S, pp.279-91.

[26] McClintock, Thomas L. (1963), "The Argument for Ethical Relativism from the Diversity of Morals", Monist, 47:S.pp.528-44.

[27] McClintock, Thomas L. (1969),“The Definition of Ethical Relativism”, Personalist, 50:S, pp.435-47.

[28] Narveson, Jan (1987), “Critical Notice of David Wong`s Moral Relativity”, Canadian Journal of Philosophy, 17:S, pp.235-58.

https://doi.org/10.1080/00455091.1987.10715913

[29] Paul Moser and Thomas Carson, eds., (2001), Moral Relativism: A Reader, Oxford University Press, Oxford, pp.32-52.

[30] Pojman, Louis P. (1990a), “Gilbert Harman's Internalist Moral Relativism.” Modern Schoolman, 68:S, pp.19-39.

[31] Russell, Bruce (1984), "Moral Relativism and Moral Realism", Monist, 67:S, pp.435-51.

https://doi.org/10.5840/monist198467324

[32] Sher, Geroge, (1980), “Moral Relativism Defended?", Mind 89:S. pp.589-94.

[33] Shomali, Mohammad A. (2001), Ethical Relativism: An Analysis of the Foundations of Morality, Islamic College for Advanced Studies Press, London,

[34] Smith, Michael (1994), The Moral Problem. Cambridge, Mass.: Blackwell.

[35] Tannsjo, Torbjorn (2007), "Moral Relativism", Philosophical Studies, $\quad$ Vol.135(2), pp.123-143. https://doi.org/10.1007/s11098-007-9083-2

[36] Tilley, John, J. (1988), “Inner Judgment and Moral Relativism.” Philosophia 18:S, pp.171-90. https://doi.org/10.1007/BF02380075

[37] Tilley, John, J. (1995), “Two Kind of Moral Relativism”, Journal of Value Inquiry, 29:S, pp.187-92. https://doi.org/10.1007/BF01079832

[38] Westermarck, E. (1932), Ethical Relativity, New York. Reprint: London 2000.

[39] Wiles, A.M. (1989), "Harman and Others on Moral Relativism", Review of Metaphysics ,42:S, pp.783-95.

[40]Wong, B. David (1991a), "Relativism”, (ed.) Peter Singer, A Companion to Ethics ,Blackwell Publishers, Oxford, pp.442-450.

[41]Wong, B. David (1991b), “ Commentary on Sayre-McCord’s Being a Realist About Relativism”, in Philosophical Studies, vol:61, pp.177-186.

[42] Wong, B. David (1992), 'Coping with Moral Conflict and Ambiguity’ in Ethics, pp.763 -784. https://doi.org/10.1086/293447

[43] Wong, B. David (1996), "Pluralistic Relativism", Midwest Studies in Philosophy, vol:20, pp.378-400.

[44] Wong, B. David (2006), Natural Moralities: A Defense of PluralisticRelativism, Oxford University Press. https://doi.org/10.1093/0195305396.001.0001 